\title{
The molecular basis of tamoxifen induction of mouse uterine epithelial cell proliferation
}

\author{
Haifan Zhang*, Tim McElrath*, Wei Tong and Jeffrey W Pollard \\ Center for the Study for Reproductive Biology and Women's Health, Departments of Developmental and Molecular Biology and OB/GYN and Women's \\ Health, Albert Einstein College of Medicine, 1300 Morris Park Avenue, Bronx, New York 10461, USA \\ (Requests for offprints should be addressed to JW Pollard; Email: pollard@aecom.yu.edu) \\ *(H Zhang and T McElrath contributed equally to this work)
}

\begin{abstract}
Tamoxifen, a selective estrogen modulator (SERM) that has found clinical utility in the treatment of breast cancer, is an antagonist in the breast and an agonist in the uterus. These agonist actions in the uterus lead to an increased risk of endometrial cancer. In this study in mice we have analyzed the mechanism of action of tamoxifen in inducing cell proliferation in the uterine luminal epithelia. Tamoxifen induces a wave of DNA synthesis in these epithelial cells with kinetics similar to those seen after $17 \beta$-estradiol $\left(\mathrm{E}_{2}\right)$ treatment. However, by these criteria of mitogenicity, it is much less potent and never achieves full estrogenicity. This uterine epithelial cell proliferation is preceded by the mobilization of cyclin D1 from the cytoplasm to the nucleus which, together with CDK4, phosphorylates members of the Rb-retinoblastoma family of proteins, $\mathrm{pRb}$ and $\mathrm{p} 107$. Subsequent to this initial nuclear accumulation of cyclin D1, cyclin E and then
\end{abstract}

cyclin $\mathrm{A}$ are induced that, together with the activation of CDK2, results in enhanced cyclin E- and cyclin A-dependent CDK2 kinase activity and further phosphorylation of $\mathrm{pRb}$ and $\mathrm{p} 107$. These actions of tamoxifen parallel those of $\mathrm{E}_{2}$. Tamoxifen also induced the classical estrogen water imbibition response. However, in this it was more potent, producing a maximal response at doses that do not affect DNA synthesis. This suggests that the uterotropic response is not an accurate predictor of the compound's hyperplasia responses. We can conclude that, in its effects on proliferation, tamoxifen acts as a classical impeded estrogen and this suggests that the AF-1 transcription activation domain of the estrogen receptor that is activated upon both $\mathrm{E}_{2}$ and tamoxifen binding to this receptor regulates these responses in the uterus.

Journal of Endocrinology (2005) 184, 129-140

\section{Introduction}

Estrogen induces cell proliferation in the uterine and mammary gland epithelium (Martin et al. 1973, Tong \& Pollard 2002). Exposure to estrogen is also the major risk factor in the development of adenocarcinomas of these organs (Travis \& Key 2003). Indeed, most of these tumors are hormone dependent for their growth before progressing to hormone independence. Consequently, endocrine ablation either by removal of the ovary or by administration of anti-estrogenic drugs has been a major therapeutic option. However, removal of estrogen has a negative impact on women's health, increasing the risk for osteoporosis and cardiovascular disease (Jordan \& Morrow 1999). Recently, a group of drugs have been developed that have selective effects on hormone responsive tissue and therefore are known as selective estrogen receptor response modulators or SERMs (Jordan \& Morrow 1999, McDonnell 1999). The most successful of them to date is tamoxifen. In large clinical trials this drug was shown to have a very significant positive impact upon disease-free survival rates in breast cancer patients because it acts as an estrogen antagonist in the mammary epithelium (Jordan \& Morrow 1999). In humans, tamoxifen is an agonist in other estrogen-responsive tissues including the uterus, where it stimulates uterine epithelial cell proliferation (Ismail 1996, Baum 1997, Jordan \& Morrow 1999). This effect upon the endometrium unfortunately results in an increased risk of endometrial cancer in patients taking the drug (Bergman et al. 2000).

It has been shown by studies, mostly in tissue culture cells, that the duration of the cell cycle is regulated by the binding of the regulatory cyclins with their cyclindependent kinase (CDK) partners (Sherr 1994). Positive activation of CDK involves assembly with their cyclin partners and phosphorylation by cyclin activating kinase. On the other hand, interaction with CDK inhibitors (CDI) negatively regulates their activity (Sherr 1996, Sherr \& Roberts 1999). The active CDKs phosphorylate their nuclear protein substrates, members of the retinoblastoma $(\mathrm{pRb})$ family of pocket proteins, which, in turn, alleviates the negative control of these proteins over certain 
transcription factors, such as the E2Fs, required for cell cycle progression (Ewen et al. 1993, Sherr 1996, Sherr \& Roberts 1999). Different cyclins act sequentially through G1, with members of the cyclin D family activating CDK4 and CDK6 first, followed by cyclin E/CDK2 at the $G_{1} / S$ phase transition and cyclin A/CDK2 throughout S phase (Ohtsubo \& Roberts 1993, Sherr 1994). In this scenario the D-type cyclins are considered to be the sensors of external signals, modulating the rate of cell division (Sherr 1994).

The high potency natural estrogen, estradiol $-17 \beta\left(\mathrm{E}_{2}\right)$, when given to ovariectomized mice results in a synchronized wave of DNA synthesis in the luminal and glandular epithelium of the uterus beginning at $6 \mathrm{~h}$ and peaking at 12-15 h after administration, followed by a wave of cell division and re-entry into another cell cycle (Finn \& Martin 1970, Kaye et al. 1972, Martin et al. 1973, 1976, Tong \& Pollard 2002). Recently, we have shown that $E_{2}$ controls the uterine epithelial cell cycle through the activation of cyclin dependent kinases which resulted in hyperphosphorylation of $\mathrm{pRb}$ and $\mathrm{p} 107$ and subsequently enhanced cell cycle progression (Tong \& Pollard 1999). Estrogen treatment of breast carcinoma cells results in a dramatic elevation of cyclin D1 mRNA and protein (Matsushime et al. 1991, 1994, Musgrove et al. 1993, 1994, Prall et al. 1997). However, in uterine epithelial cells in vivo there was only a moderate induction of cyclin D1 by $\mathrm{E}_{2}$ and most of this was at a later stage than the phosphorylation of $\mathrm{pRb}$ (Tong \& Pollard 1999). Instead, $\mathrm{E}_{2}$ mobilized cyclin D1 and to a lesser extent CDK4 from the cytoplasm to the nucleus, thus giving the active kinase complex access to its nuclear localized $\mathrm{pRb}$ family of substrates (Tong \& Pollard 1999). These data suggest that the mobilization of cyclin D1 into the nucleus is a central regulatory point for estrogen action in the uterus.

In the mouse uterus, tamoxifen is an agonist inducing epithelial cell proliferation while showing little to no antagonistic effect in the presence of $\mathrm{E}_{2}$ (Martin \& Middleton 1978, Klotz et al. 2000). Long-term administration induces persistent changes in the uterus including cystic hyperplasia in the glands (Martin \& Middleton 1978). This contrasts with the rat where tamoxifen was as effective as ovariectomy in reducing proliferating cell nuclear antigen (PCNA) expression, a marker for cell proliferation, although the effects were somewhat cell type specific (Rumpel et al. 1995), and in chickens where it is fully antagonistic without estrogenic properties (Sutherland et al. 1977). Humans appear to be more similar to mice than to rats in their uterine responses, since tamoxifen acts agonistically stimulating cell proliferation (Ismail 1996, Jordan \& Morrow 1999, Willen et al. 2002). These differences could be mediated through different metabolic routes. However, there have been no speciesspecific variations in estrogen metabolism identified to date. This has led to the concept of target site-specific regulation and many have focused upon differential estrogen receptor (ER) modulation by tamoxifen (Jordan \& Morrow 1999).

There have been few studies on the molecular basis of this agonistic action in the uterus. Some have analyzed the induction of specific estrogen-responsive genes that might affect cell proliferation such as transforming growth factor- $\beta 1$, vascular endothelial growth factor (VEGF) and insulin-like growth factor (IGF)-I/IGF binding proteins (Hung \& Pollak 1995, Sartor et al. 1995, Hyder et al. 1996, Klotz et al. 2000, Mueller et al. 2003), but none have specifically addressed the control of the cell cycle machinery in uterine epithelial cells with the exception of some studies on cyclin D expression (Geum et al. 1997). However, in cancer cells in culture there have been several studies that have explored the antagonistic effect of tamoxifen (Watts et al. 1994, Planas-Silva \& Weinberg 1997), although these actions have not necessarily been dependent upon the ER (Lee et al. 2000). A central mechanism appears to be through the induction of the CDIs, p21 ${ }^{\mathrm{WAF} 1}$ and $\mathrm{p} 27^{\mathrm{KIP} 1}$, combined with a reduction in cyclin D1 protein that acts to inhibit cyclin D/CDK4 and cyclin E/CDK2 activity and arrest cell cycle progression (Wilcken et al. 1997, Lee et al. 1999, 2000, DoisneauSixou et al. 2003). Interestingly, over-expression of cyclin D1 (Wilcken et al. 1997) or cyclin E can alleviate tamoxifen inhibition of MCF-7 cells in culture (Dhillon \& Mudryj 2002). In some cases cyclin E can also replace cyclin D1 function in regulating the cell cycle (Lukas et al. 1997, Geng et al. 1999). Furthermore, over-expression of cyclin E can stimulate cell cycle transit without influencing cyclin $\mathrm{D} 1 / \mathrm{CDK} 4$ activity or $\mathrm{pRb}$ phosphorylation (Lukas et al. 1997). Since cyclin D1 appears to be a major point of control for $\mathrm{E}_{2}$ regulation of the uterine epithelium, then an explanation for tamoxifen's agonist role without fully activating the estrogen receptor may be that tamoxifen exerts its action in a manner different from that of $E_{2}$ through regulating other components of the cell cycle such as cyclin E. Given the diverse receptor- and non-receptor-mediated effects of tamoxifen and its importance in breast cancer chemotherapy in humans, we analyzed the proliferation response to tamoxifen in the mouse uterine epithelial cells in vivo and its effects on the cyclin-dependent cell cycle machinery in these cells. We found that it is an impeded estrogen with a $\simeq 200000$-fold lower potency than $\mathrm{E}_{2}$ but that it exerts its effects on cell proliferation in a manner similar to $\mathrm{E}_{2}$.

\section{Materials and Methods}

\section{Animals and treatment}

Adult female CD1 mice (Charles River, Wilmington, MA, USA), maintained in a 12-h light:12-h darkness cycle and weighing 25-30 g, were ovariectomized, rested for two weeks, followed by two days of priming with $\mathrm{E}_{2}$ as described (Tong \& Pollard 1999). Six days later, groups 
of 3-5 mice were given one of the following treatments: (i) peanut oil, (ii) $50 \mathrm{ng} \mathrm{E}_{2}$, (iii) a range of concentrations $(0 \cdot 125-1 \cdot 5 \mathrm{mg} / \mathrm{mouse})$ of tamoxifen. All hormones were purchased from Sigma and administered subcutaneously in peanut oil.

At various times after hormone treatment mice were killed, uteri removed and weighed, and either processed for immunohistochemistry or the luminal epithelium was removed for biochemical analysis as described previously (Tong \& Pollard 1999). In some cases, to assess the percentage of cells in S-phase, BrdU was given intraperitoneally $2 \mathrm{~h}$ before killing as described by Tong \& Pollard (1999).

\section{Immunohistochemistry}

Uteri were fixed overnight in Bouin's solution or peroxide-lysine- $2 \%$ paraformaldehyde $-0.5 \%$ glutaldehyde (PLPG) and processed for paraffin embedding. Transverse sections $(5 \mu \mathrm{m})$ through the mid-point of the uterus were prepared and immunostained for BrdU incorporation, or for PCNA, cyclin A, CDK2, CDK4 or cyclin D1 protein as described (Tong \& Pollard 1999). Polyclonal antibodies to CDK2 (sc-163), CDK4 (sc-260), p107 (sc-318) and cyclin A (sc-596) were obtained from Santa Cruz Biotechnology, Santa Cruz, CA, USA and validated by peptide inhibition and titration as described (Tong \& Pollard 1999). Monoclonal antibodies to $\mathrm{pRb}$ (G3-245) were obtained from Pharmingen (San Diego, CA, USA), for cyclin D1 (DCS-6) they were obtained from Neomarkers (Freemont, CA, USA) and for PCNA (PC10) they were obtained from Boehringer Mannheim. Controls also included incubation in normal serum corresponding to the source of the antibody used and omission of the primary antibody. These were uniformly negative. To determine the percentage of nuclear positive luminal and glandular epithelial cells for each of these antibody stains, all the epithelial cells were scored in representative sections from the mid-point of the uterus and means \pm S.D. from a minimum of 6 mice were derived.

\section{Biochemical analysis of cell cycle regulatory proteins}

Uterine epithelial cell lysates were prepared in either the gel electrophoresis buffer or in kinase buffer, as described in detail before (Tong \& Pollard 1999), at various times after hormone treatment using a method that gave an epithelial extract of $<95 \%$ purity (Fagg et al. 1979, Tong \& Pollard 1999). Protein concentration was measured using the Bradford reagent. Equal amounts of protein per treatment group were separated by SDS-gel electrophoresis and transferred to Immonobilon $\mathrm{P}$ membrane (Millepore, Billerica, MA, USA). After blocking nonspecific binding using dried milk, filters were probed with antibodies against cyclin D1, E and A, pRb and p107, and CDK4, CDK2 and PCNA as described (Tong \& Pollard
1999). Specific binding was detected using an enhanced chemoluminescence system after incubation with an appropriate secondary antibody linked to horseradish peroxidase as described (Tong \& Pollard 1999). The immunodetection for each protein was shown to be in the linear portion of the curve by titration of the lysates and antibody, and the signal was quantified by densitometry (Tong \& Pollard 1999).

Immune complex kinase assays were performed after immunoprecipitation of the uterine lysates with anticyclin E, anti-cyclin A, anti-CDK4 and anti-CDK2 antibodies as described (Tong \& Pollard 1999, Chen \& Pollard 2003). Histone H1 was used as the substrate for anti-cyclin E, cyclin A and CDK2 immunoprecipitates while GSK pRb (Amino acids 769-921, Santa Cruz) was used as the substrate for CDK4. The reaction products were separated by SDS-gel electrophoresis followed by autoradiography as described (Tong \& Pollard 1999). All experiments involving protein analysis were derived from five mice per group and were repeated at least twice with similar results. Blots shown are representative of these repeat experiments.

\section{Statistical analysis}

Statistical analysis was performed using ANOVA with Dunnett's multiple comparisons test to determine the significance of the effect of tamoxifen at various times/ doses versus the control. For single time point comparisons between $\mathrm{E}_{2}$ and tamoxifen treatments, Student's $t$-test was used.

\section{Results}

Dose-response to tamoxifen

A single injection of $50 \mathrm{ng} \mathrm{E}_{2}$ to ovariectomized mice stimulates uterine luminal and glandular cell proliferation with a peak of cells detected with anti-BrdU antibody in S-phase $15 \mathrm{~h}$ after administration. At this stage, 90\% of cells have incorporated BrdU. This dose of $\mathrm{E}_{2}$ has been demonstrated to be maximal (Martin et al. 1973). Consistent with this induction of DNA synthesis there is a concurrent nuclear localization of PCNA, the $\delta$-sub-unit of DNA polymerase, and cyclin A synthesis and its nuclear localization (Tong \& Pollard 1999). $E_{2}$ also stimulates uterine edema and this is often used as a surrogate marker for estrogenicity (Martin et al. 1973). Consequently, we used the four parameters of BrdU incorporation, PCNA nuclear localization, cyclin A synthesis and nuclear localization, and uterine edema to determine the responsiveness of the mouse uterus to tamoxifen over a range of doses from 0.125 to $1.5 \mathrm{mg} /$ mouse. These responses were measured at $16 \mathrm{~h}$ after hormone administration because this is also the time point of maximal response (see below). 

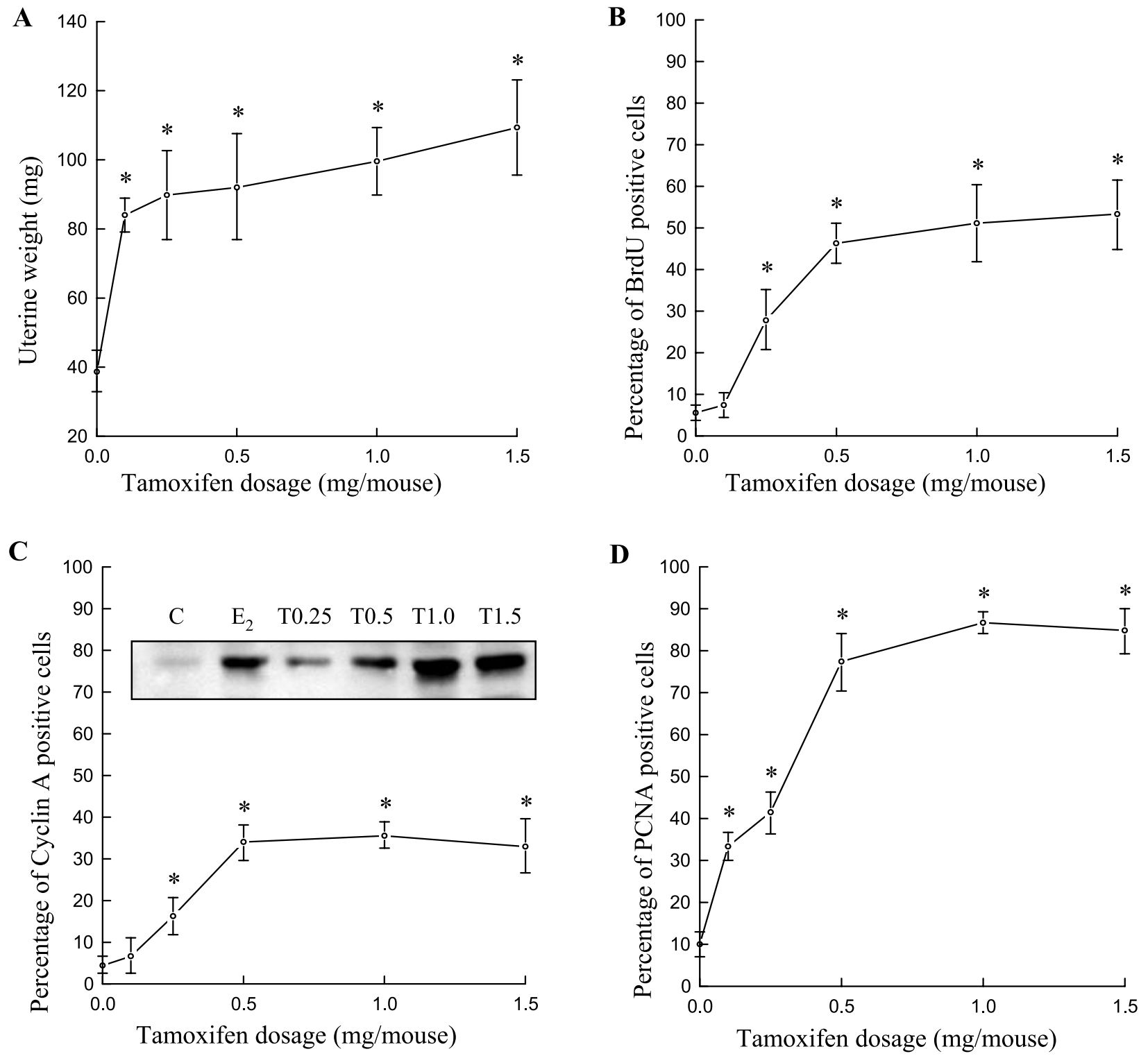

Figure 1 Dose-responses for tamoxifen in the uterus. Ovariectomized mice were given tamoxifen subcutaneously over a range of doses from 0 to $1.5 \mathrm{mg} / \mathrm{mouse}$ as shown. Sixteen hours after treatment mice were killed and the following parameters determined as described in the Materials and Methods section. (A) Wet weight; (B-D) luminal epithelial cells positive for BrdU (B), cyclin A nuclear (C) and PCNA nuclear (D) staining. The insert in (C) shows epithelial cell cyclin A protein concentration at each dose as determined by Western blotting of equal concentrations of total epithelial cell lysates. $\mathrm{E}_{2}, 50 \mathrm{ng} \mathrm{E}_{2} ; \mathrm{C}$, untreated control; $\mathrm{T}$, tamoxifen (dose, mg/mouse). Results are means \pm S.D. ${ }^{*} P<0 \cdot 01$, significantly different from the control. The effect of tamoxifen was highly significant for all parameters $(P<0 \cdot 001)$.

Sixteen hours post-administration tamoxifen induced a doubling of uterine wet weight even at the lowest dose of $0.125 \mathrm{mg} / \mathrm{mouse}$, with little further increase up to $1.5 \mathrm{mg} / \mathrm{mouse}$ (Fig. 1A; $P<0 \cdot 001$ ). This indicates a nearly maximal response at $0.125 \mathrm{mg} /$ mouse. In contrast, a tamoxifen dose of $0 \cdot 125 \mathrm{mg} / \mathrm{mouse}$ did not induce an increase in cells incorporating BrdU (Fig. 1B). This required $0.25 \mathrm{mg} /$ mouse to produce a statistically significant increase $(P<0 \cdot 01)$, with the plateau of response attained at $0.5 \mathrm{mg} /$ mouse when approximately $50 \%$ of cells were in DNA synthesis (Fig. 1B). This was significantly lower than the response to $\mathrm{E}_{2}$ (data not shown; $P<0 \cdot 001)$. Consistent with this increase in DNA synthesis, there was a dose-related increase in the concentration of cyclin A measured by Western blotting with anti-cyclin A antibodies in uterine luminal epithelial lysates (Fig. 1C, insert), although maximal amounts were not detected until $1 \cdot 0 \mathrm{mg} /$ mouse was administered, at which point it was 
A

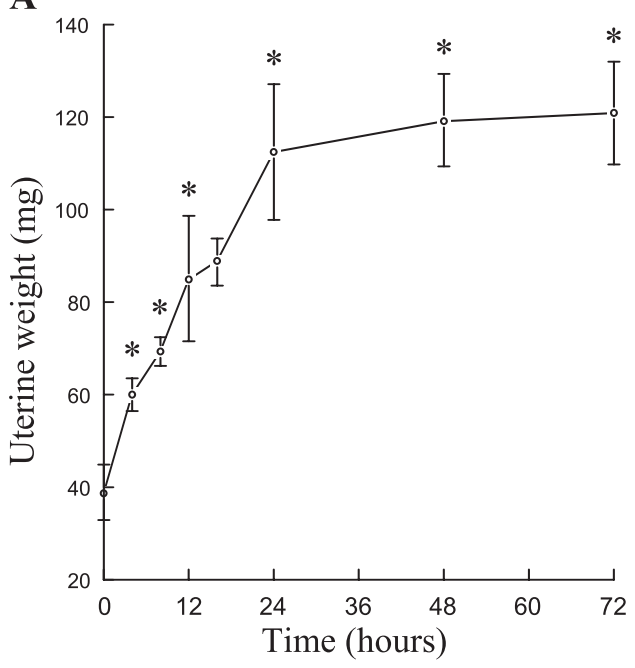

B

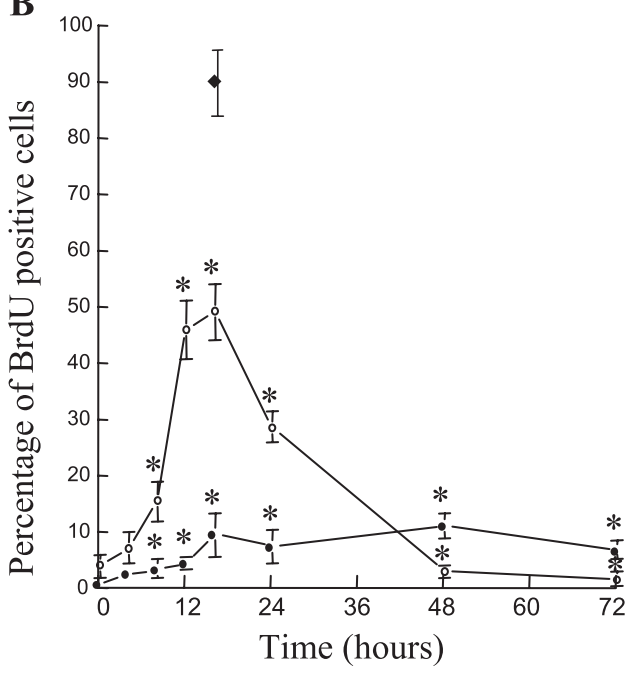

C

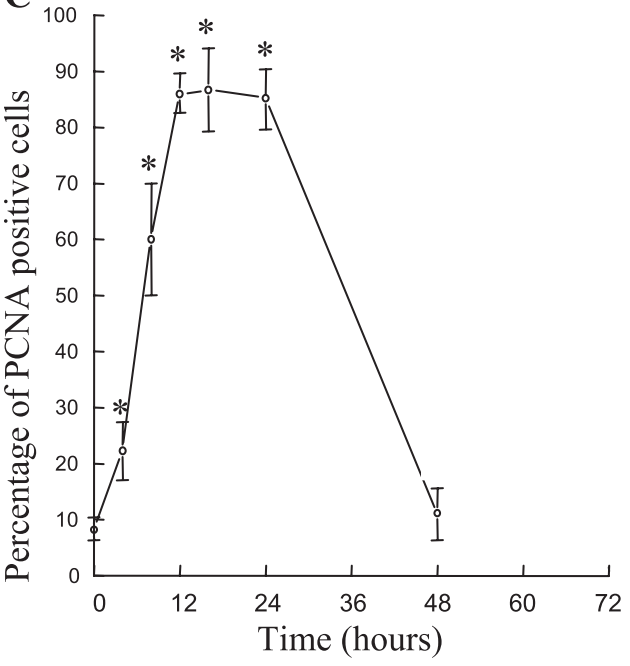

D
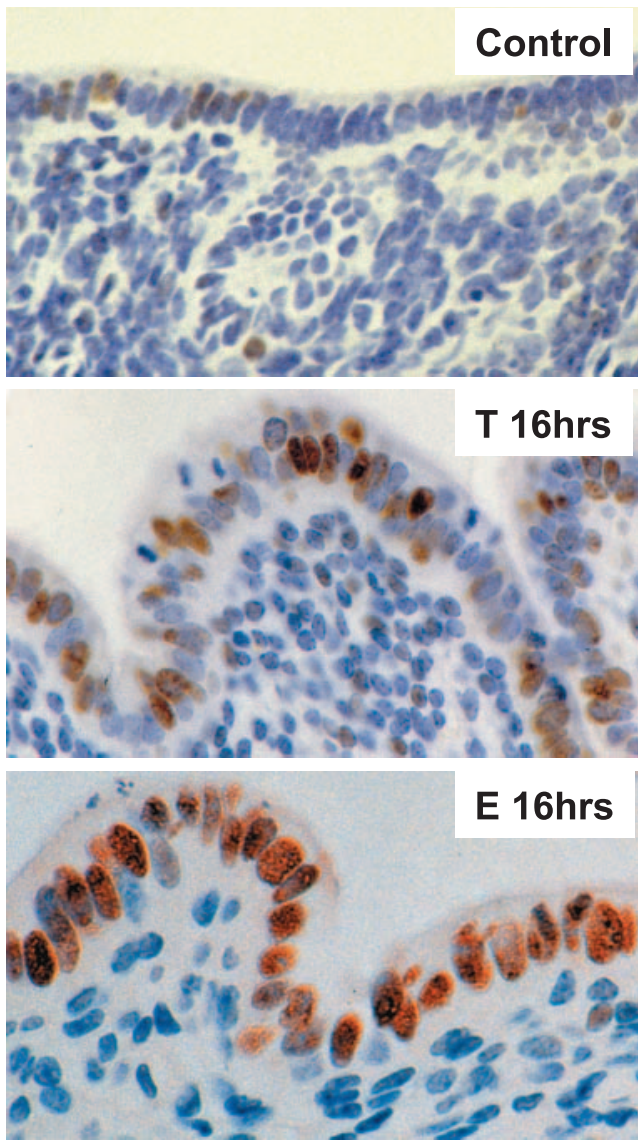

Figure 2 Time course of responses to tamoxifen in the uterus. Ovariectomized mice were treated with $1.0 \mathrm{mg} /$ mouse tamoxifen and killed at the times show on the $\mathrm{X}$-axis $(\mathrm{A}-\mathrm{C})$. (A) Uterine wet weight; (B) \% of cells positive for BrdU staining in the luminal $(\bigcirc)$ and glandular $(\bullet)$ epithelium; $(\bullet)$ BrdU-positive cells in mice given $50 \mathrm{ng} \mathrm{E}_{2}$ subcutaneously at time zero. (C) PCNA nuclear-positive luminal epithelial cells. In A-C results are shown as means \pm S.D. ${ }^{*} P<0 \cdot 01$, significantly different from control untreated mice. The effect of tamoxifen was highly significant in all groups $(P<0 \cdot 001)$. (D) Immunostaining showing BrdU-positive cells in transverse sections of control, tamoxifen $(\mathrm{T})$ and $\mathrm{E}_{2}(\mathrm{E})$-treated mice killed $16 \mathrm{~h}$ after administration. BrdU-positive cells are shown by the reddish-brown immunostain. 
induced to a similar level to that attained after treatment with $50 \mathrm{ng} \mathrm{E}_{2}$. Cyclin A acts in concert with its CDK2 partner in the nucleus to phosphorylate nuclear localized $\mathrm{pRb}$-family substrates required for progression through $\mathrm{S}$ phase and it is therefore an index of DNA synthesis (Sherr 1996). Thus the percentage of cyclin A nuclear positive cells was scored following immunohistochemistry of transverse uterine sections using anti-cyclin $\mathrm{A}$ antibodies. The lowest dose of $0.125 \mathrm{mg}$ did not cause a significant elevation in cyclin A positive cells. This required $0.25 \mathrm{mg}$ $(P<0 \cdot 01$, control vs tamoxifen treated) with the doseresponse reaching a plateau at $0.5 \mathrm{mg} /$ mouse, exactly mimicking the dose-response of incorporation of BrdU, although with only $30 \%$ of the epithelial cells being scored positive for this cyclin at this time-point (Fig. 1C).

The nuclear localization of PCNA is also considered to be a marker of cell proliferation (Hyde-Dunn \& Jones 1997). Tamoxifen significantly $(P<0 \cdot 001)$ increased the percentage of cells with nuclear-associated PCNA and this reached a maximum of $80 \%$ positive cells at a dose of $0.5 \mathrm{mg} / \mathrm{mouse}$ (Fig. 1D). However, just as for uterine edema, there was also a significant response compared with untreated mice $(P<0.01)$ at $0.125 \mathrm{mg} / \mathrm{mouse}$ with $\sim 30 \%$ of the cells being positive for nuclear PCNA (Fig. 1D).

In these preliminary experiments we have shown that tamoxifen induces a significant dose-dependent increase in DNA synthesis in the luminal epithelium of ovariectomized mice. Given that $0.5 \mathrm{mg} /$ mouse marked the inflection point of the dose-response curve, $1.0 \mathrm{mg} / \mathrm{mouse}$ was chosen for subsequent experiments because this produced a maximal response for all four parameters measured. Since $50 \mathrm{ng} /$ mouse $\mathrm{E}_{2}$ is a maximal dose, this indicates that tamoxifen is $\sim 200000$ times less potent than $E_{2}$ in this organ and never achieves full estrogenicity.

\section{Time course of uterine response to tamoxifen}

We next determined the time-course of responses to $1.0 \mathrm{mg} /$ mouse tamoxifen in ovariectomized, primed mice. This dose induced a dramatic and significant $(P<0 \cdot 001)$ increase in wet weight with a $50 \%$ increase within $4 \mathrm{~h}$ of administration $(P<0 \cdot 01$, control vs $4 \mathrm{~h}$ tamoxifen treated). This progressively increased over time to reach approximately threefold the control weight at $24 \mathrm{~h}$ where it remained throughout the duration of the experiment until $72 \mathrm{~h}$ post-injection (Fig. 2A). The pattern of BrdU incorporation into luminal epithelium cells followed that observed following a single injection of $\mathrm{E}_{2}$ (Martin et al. 1973) with the first significant increase in BrdU-positive luminal epithelial cells found at $8 \mathrm{~h}$ after injection (Fig. 2B; $P<0 \cdot 01)$. This value reached a peak at $12-16 \mathrm{~h}$, followed by a steady decline to below control steady-state values by $48 \mathrm{~h}$ (Fig. $2 \mathrm{~B}$ ). The peak value of $\sim 50 \%$ of luminal epithelial cells incorporating BrdU was significantly less than the $\sim 90 \%$ observed following a single injection of
$50 \mathrm{ng} \mathrm{E}_{2}$ (Fig. 2B,D; $P<0 \cdot 001$ Student's $t$-test). This effect on BrdU incorporation is illustrated in Fig. 2D. BrdUpositive cells in the glandular epithelium followed a similar pattern except the amplitude was much lower both in the untreated control and in the drug-treated group (Fig. 2B). Furthermore, the incorporation of BrdU into these cells persisted over the $72 \mathrm{~h}$ of the experiment.

Nuclear association of PCNA in luminal epithelial cells was detected earlier and persisted longer than the incorporation of BrdU. Thus there was a significant increase at $4 \mathrm{~h}$ after treatment $(P<0 \cdot 01)$. However, the plateau of PCNA-positive cells at $12 \mathrm{~h}$ after injection was achieved at the same time as the number of BrdU-positive cells but thereafter this persisted until $24 \mathrm{~h}$ as compared with the $16 \mathrm{~h}$ peak for BrdU incorporation, before declining to untreated ovariectomized control levels at $72 \mathrm{~h}$ (Fig. 2C). This shows that PCNA persists in the nucleus even when cells have ceased DNA synthesis.

These data confirm and significantly extend previous studies (Martin \& Middleton 1978) that conclude that the proliferative responses to tamoxifen in uterine epithelial cells show a similar time course to those observed after $\mathrm{E}_{2}$ treatment.

\section{Tamoxifen regulation of the cell cycle machinery}

The hyperphosphorylation of the $\mathrm{pRb}$ family of proteins is thought to be central to the regulation of the mammalian cell cycle (Sherr 1996). Consequently, we examined the phosphorylation of $\mathrm{pRB}$ and $\mathrm{p} 107$ in response to $1.0 \mathrm{mg}$ tamoxifen for up to $48 \mathrm{~h}$ post-treatment. In the control untreated uterine epithelial lysates, both $\mathrm{pRb}$ and p107 mostly run as a single band on SDS-PAGE corresponding to the hypo-phosphorylated forms of these molecules (Fig. 3) (Tong \& Pollard 1999). Eight hours after tamoxifen treatment phosphorylated bands characterized by a lower electrophoretic mobility were visible for both $\mathrm{pRb}$ and p107. These phosphorylated forms increased and persisted until $24 \mathrm{~h}$ after treatment before they declined $48 \mathrm{~h}$ post treatment (Fig. 3).

Phosphorylation of these pocket proteins is by the sequential activity of cyclin D1/CDK4 and 6, cyclin E/CDK2 and cyclin A/CDK2 (Roberts 1999). The luminal epithelial response to $E_{2}$ also follows this pattern of sequential kinase activation with the exception that cyclin $\mathrm{D} / \mathrm{CDK} 4$ protein and activity is only slightly affected by $\mathrm{E}_{2}$. Instead, cyclin D1 accumulates in the nucleus where it gains access to its substrates (Tong \& Pollard 1999). Thus, we measured cyclin D1-, E- and A-associated kinase activities and the cellular localization of cyclin D and A in the uterine luminal epithelium following tamoxifen treatment of ovariectomized mice. As had been determined for $\mathrm{E}_{2}$ treatment, the luminal epithelial concentration of cyclin D1 showed only modest changes following tamoxifen treatment, with an initial small decline at $4 \mathrm{~h}$ followed by a doubling between 16 and $24 \mathrm{~h}$ after administration 

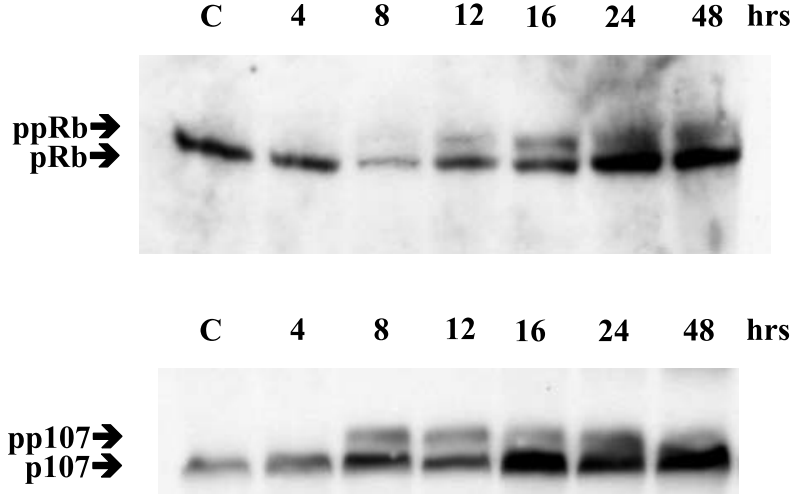

Figure 3 Tamoxifen induces phosphorylation of the Rb family of proteins in the uterine luminal epithelium. Western blots of SDS-PAGE gels upon which were separated equal protein concentrations of uterine epithelial protein extracts isolated from mice at the times indicated following tamoxifen treatment. Blots were probed with anti-pRb (upper panel) and anti-p107 (lower panel) antibodies. In each case the slower migrating band represents the hyper-phosphorylated form (ppRb and pp107) of the protein. $\mathrm{C}$, control untreated ovariectomized mice.

(Fig. 4A). This is similar to that described following $\mathrm{E}_{2}$ treatment (Tong \& Pollard 1999). CDK4 is an abundant protein whose cellular concentration remains constant and unaffected by $\mathrm{E}_{2}$ (Tong \& Pollard 1999). This, therefore, has been used as a loading control for these experiments and per $\mathrm{mg}$ of protein loaded onto the gel, CDK4 remained constant over the $72 \mathrm{~h}$ treatment period studied (Fig. 4A).

Consistent with these relatively small changes in cyclin D1 protein over the time course studied, the total CDK4 activity in epithelial lysates was relatively unchanged over the first $12 \mathrm{~h}$ after administration as assessed by an immune-complex kinase assay using $\mathrm{pRb}$ as a substrate (Fig. 4A). This activity declined modestly 16 to $24 \mathrm{~h}$ after tamoxifen treatment (Fig. 4A). However, immunohistochemical studies of the localization of cyclin D1 in luminal epithelium using an anti-cyclin D1 antibody indicated a marked nuclear accumulation $(P<0 \cdot 01)$ at $8 \mathrm{~h}$ after treatment (Fig. 4B,C). This nuclear accumulation continued to reach a peak at $16 \mathrm{~h}$ when $\sim 50 \%$ of cells were positive, before declining at $24 \mathrm{~h}$ to return to control levels by $48 \mathrm{~h}$ after treatment (Fig. 4B,C). Thus, as described for $\mathrm{E}_{2}$ action (Tong \& Pollard 1999) it is the nuclear localization of cyclin D1 that brings the CDK4 activity to the nucleus, thereby allowing phosphorylation of the $\mathrm{pRb}$ family of proteins and initiation of the uterine epithelial cell cycle.

After the initial phosphorylation of $\mathrm{pRb}$ and $\mathrm{p} 107$ by cyclin D1/CDK4 or CDK6, the subsequent phosphorylation is performed by CDK2 in association with cyclin $\mathrm{E}$ or cyclin A. As assessed by Western blotting, tamoxifen produced a modest elevation in cyclin E concentrations in the luminal epithelial cells approximately $8 \mathrm{~h}$ after administration and this declined between 24 and $48 \mathrm{~h}$ to below the control untreated levels (Fig. 5A). In contrast and consistent with the documented sequence of events following $\mathrm{E}_{2}$ treatment of the uterus (Tong \& Pollard 1999), cyclin A concentration in the uterine epithelial cells did not show a change until $12 \mathrm{~h}$ after tamoxifen administration after which it reached a peak at 16-24 h before declining at $48 \mathrm{~h}$ (Fig. 5A). This was paralleled by the detection, by immunostaining, of nuclear cyclin $\mathrm{A}$ at 12 and $16 \mathrm{~h}$ post-tamoxifen treatment with an anti-cyclin $\mathrm{A}$ antibody (Fig. 5B).

CDK2 levels showed relatively minor changes in concentration following tamoxifen treatment of ovariectomized mice (Fig. 5A). However, tamoxifen produced a marked increase in the active form of CDK2 (Thr160p; Fig. 5A) that is detected as a band with greater electrophoretic mobility than the inactive form. This increased mobility is due to the removal of two inhibitory phosphorylations and the addition of an activating phosphorylation at Thr160, resulting in a total reduction in charge of one phosphate group (Fig. 5A). This active form begins to increase $4 \mathrm{~h}$ after tamoxifen treatment and reaches its maximum between 16 and $24 \mathrm{~h}$ post-tamoxifen treatment. Consistent with the appearance of this activated form of CDK2, the activity of cyclin E, cyclin A and total CDK2 kinase activity in the epithelial cells, as measured by immune-complex kinase assays, progressively increased following tamoxifen treatment of ovariectomized mice (Fig. 5C). The activity of cyclin E-associated kinase reached a maximum at $16 \mathrm{~h}$ before rapidly declining (Fig. 5C) while cyclin A-associated activity increased to its maximal level $12-16 \mathrm{~h}$ post-treatment and this was sustained until $24 \mathrm{~h}$ (Fig. 5C). This is consistent with the induction of cyclin A protein (Fig. 5A). The peak of total CDK2 activity was detected at $16 \mathrm{~h}$ after treatment and this is at the time of maximal active form detected on the Western blots (Fig. 5C) and co-incident with the peak in BrdU incorporation (Fig. 2B). The persistence of this total CDK2 activity through $24 \mathrm{~h}$ (Fig. $5 \mathrm{C}$ ) is due to the cyclin A-associated activity. This is consistent with the role of CDK2 in promoting the G1 to S-phase transition and of its requirement in association with cyclin $\mathrm{A}$ for the transit of S-phase.

\section{Discussion}

Estrogens play an essential role in the development and function of the female reproductive tract. In adult mice at estrus and in humans during the proliferative phase, $\mathrm{E}_{2}$ is the primary mitogen to the uterine epithelial cells acting through its receptor transcription factor, ER $\alpha$ (Tong \& Pollard 2002). Estrogens are also mitogenic in the mammary epithelium that is also a target organ because of 
$\mathbf{A}$

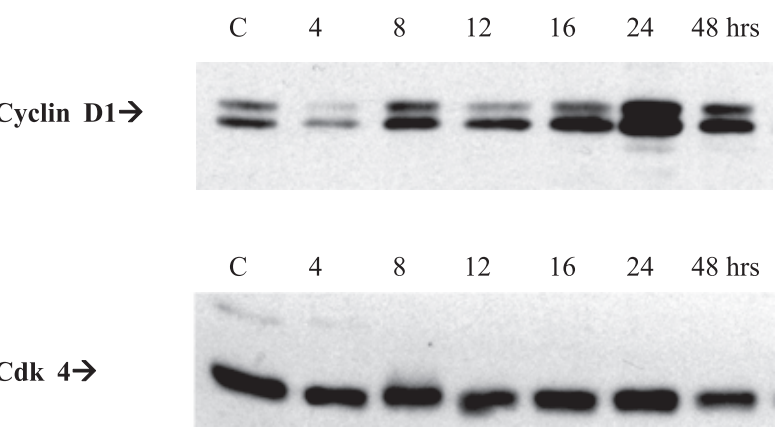

$\begin{array}{lllllllll}\text { Cdk } 4 & \text { NRS } & \text { C } & 4 & 8 & 12 & 16 & 24 & 48 \text { hrs }\end{array}$

GST-Rb $\rightarrow$
C

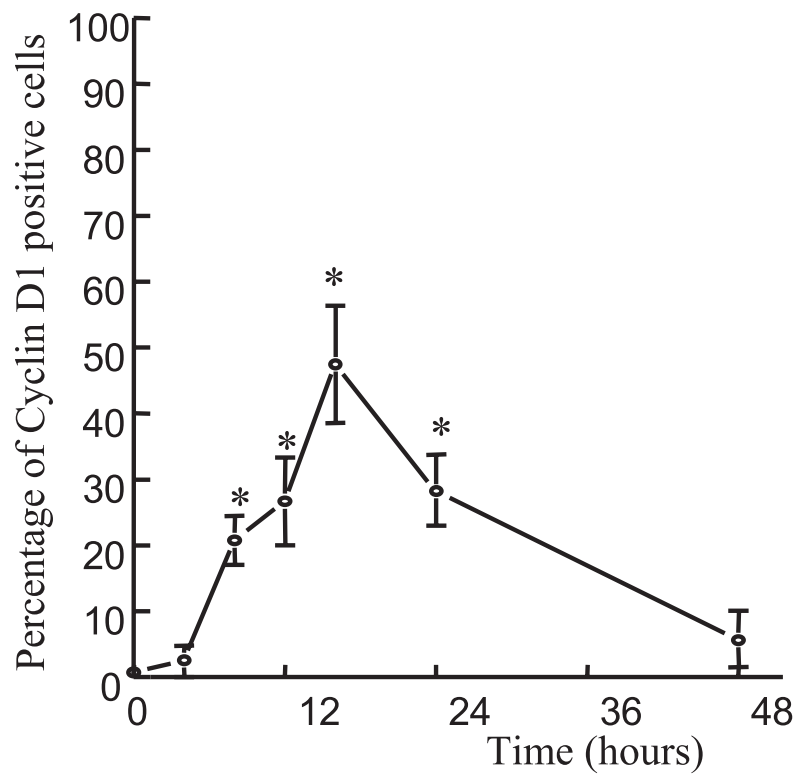

B
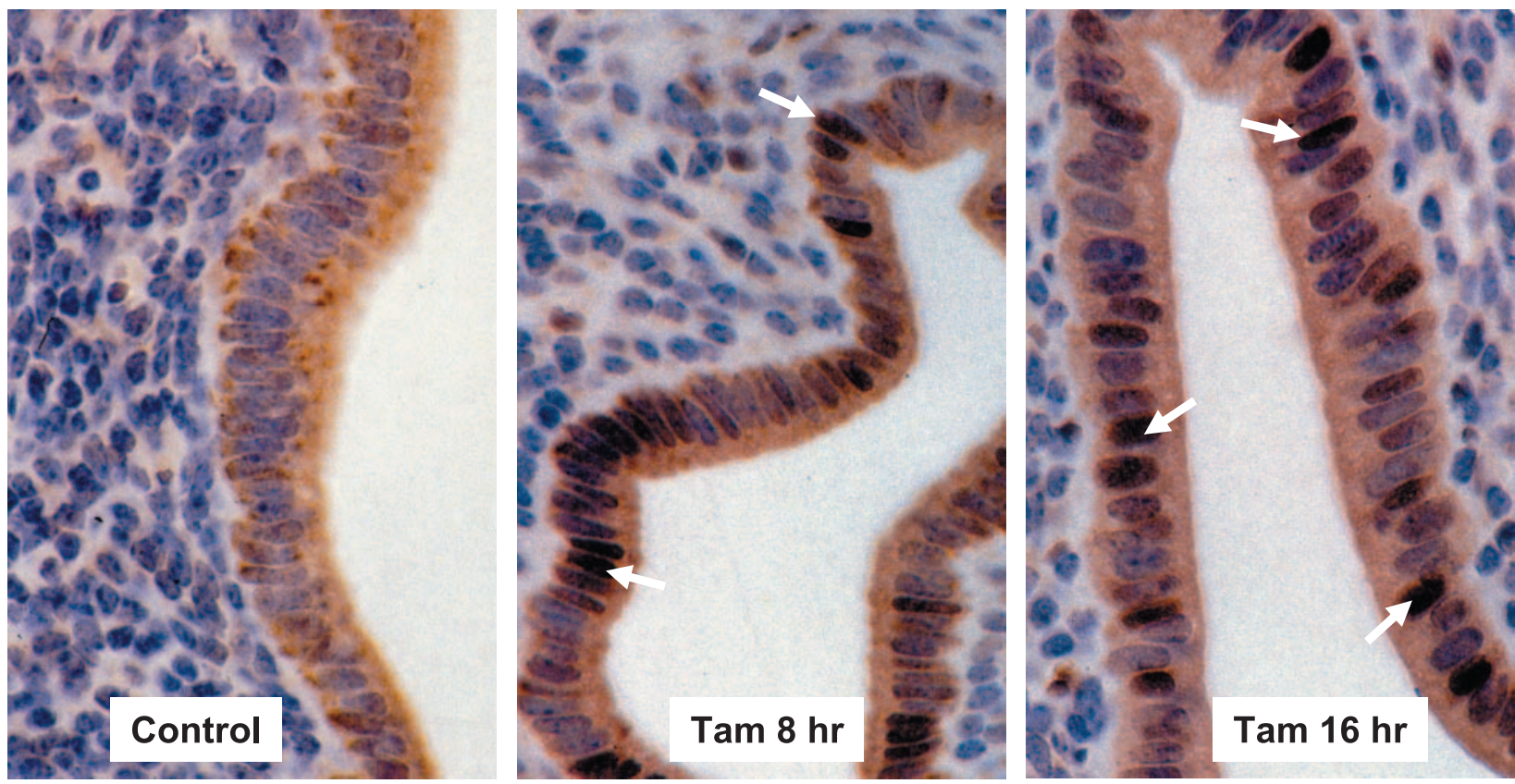

Figure 4 Tamoxifen induces cyclin D1 translocation from the cytoplasm to the nucleus. (A) Equal protein concentrations of lysates of uterine epithelial cells isolated from ovariectomized mice treated with tamoxifen at the times shown were analyzed by Western blotting for cyclin D1 (top) and CDK4 (middle) concentrations. The other portion of the lysates was used for measurement of CDK4 kinase activity (bottom) by an anti-CDK4 immune-complex kinase assay using GST-Rb as a substrate. NRS, normal rabbit serum control for non-specific kinase activity. (B) Transverse sections of uteri isolated at 8 and $16 \mathrm{~h}$ after tamoxifen (Tam) treatment and immunostained with anti-cyclin D1 antibody. Control, untreated ovariectomized control. Arrows indicate some nuclear-positive cells. (C) Percentage of luminal epithelial nuclei stained positive for cyclin D1 at different times after tamoxifen treatment. Results are means \pm S.D. ${ }^{*} P<0 \cdot 01$, significantly different from control untreated mice. The effect of tamoxifen was highly significant $(P<0 \cdot 001)$. 
A
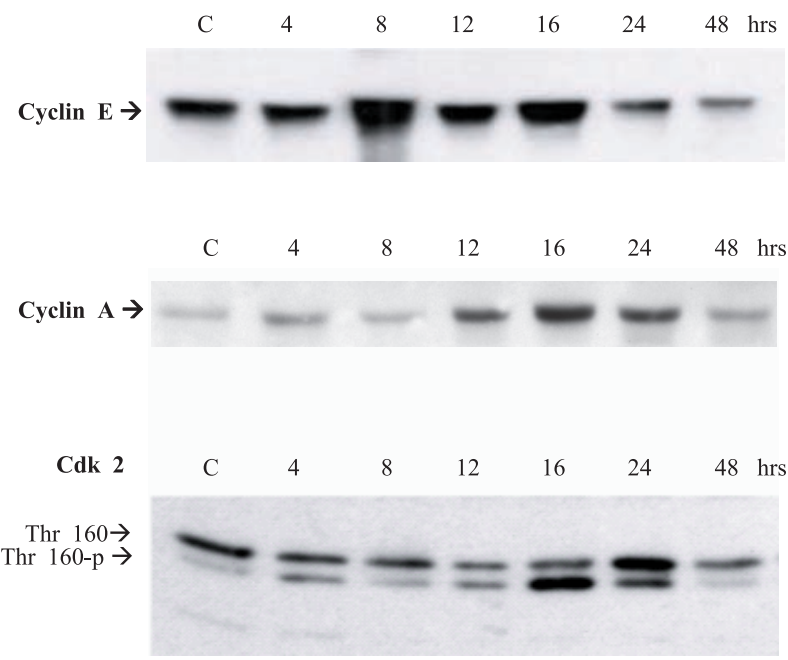

C

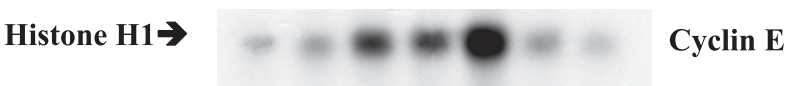

mineme

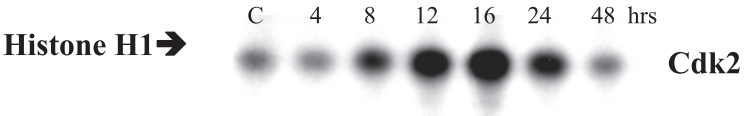

B
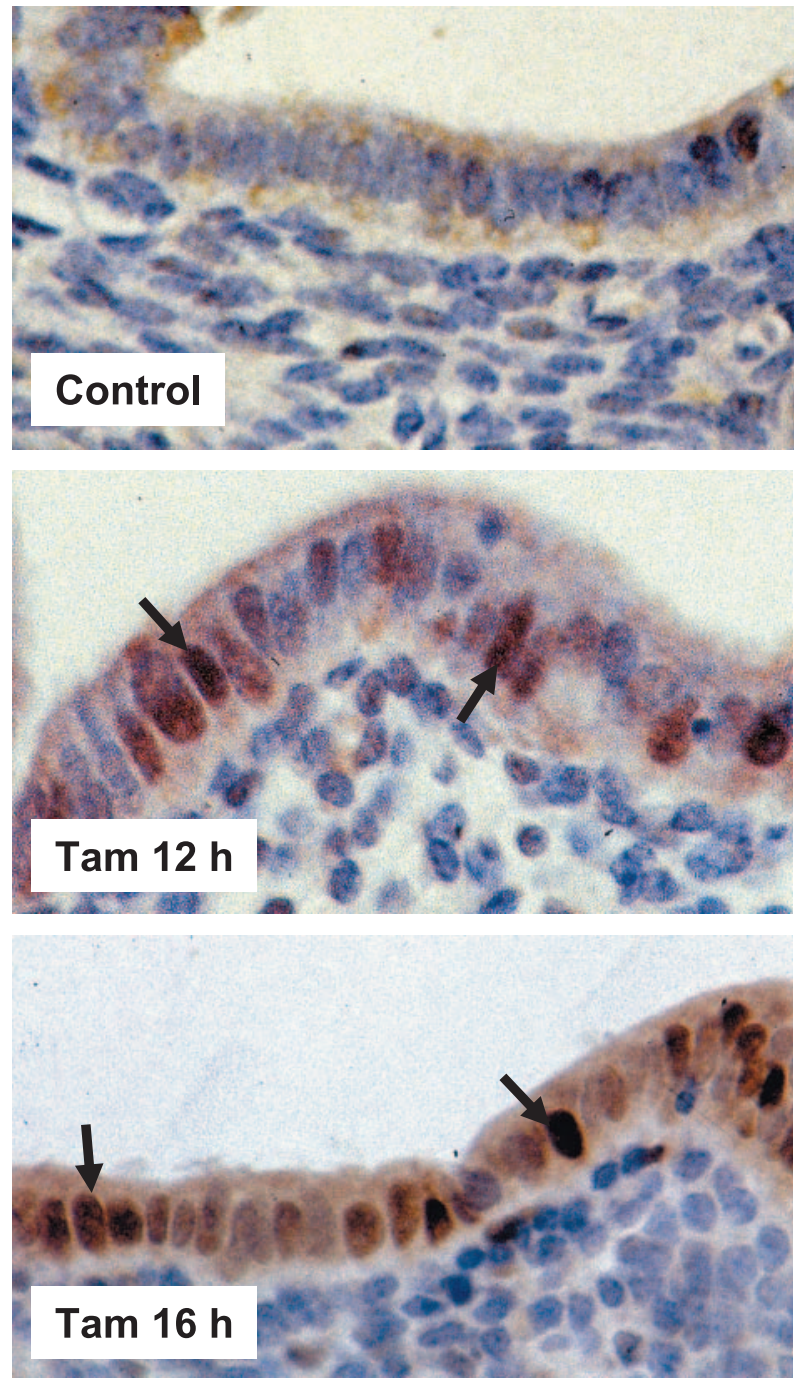

Figure 5 Tamoxifen increases cyclin E- and A-associated CDK2 activity. (A) Western blots of equal protein concentrations of uterine epithelial cell lysates isolated at the times indicated, probed with anti-cyclin E, anti-cyclin A and anti-CDK2 antibodies as indicated. The active form of CDK2 runs as a band with a higher electrophoretic mobility (Thr160-p) than the inactive form (Thr 160). (B) Immunohistochemical localization of cyclin A on transverse sections of mouse uteri treated with tamoxifen (Tam) for the times shown. Arrows indicate some positive cells. (C) Immune-complex CDK2-kinase assays using histone $\mathrm{H} 1$ as a substrate of the other half of the lysates shown in A to measure cyclin E (top) and cyclin A (middle) -associated CDK2 activity and total CDK2 activity (bottom) at various times after tamoxifen treatment. C, ovariectomized untreated control.

expression of the ER (Bocchinfuso \& Korach 1977, Daniel et al. 1987, Haslam 1988). In both the uterine and mammary epithelium, $\mathrm{E}_{2}$ activates the cyclin/cyclindependent kinase cell cycle machinery. First, members of the cyclin D family, together with their partners CDK4 and CDK6, are activated followed by induction of cyclin E- and cyclin-A-CDK2 activity. This results in the sequential phosphorylation of the central cell cycle regulatory molecule, $\mathrm{pRb}$, and progression into S-phase
(Clarke \& Sutherland 1990, Tong \& Pollard 2002, Doisneau-Sixou et al. 2003). In the uterus, in contrast to mammary epithelial cells in culture, $E_{2}$ does not result in an elevation of cyclin D1 early in the cell cycle but instead mobilizes a pre-existent cytoplasmic pool to move into the nucleus. Similarly, cyclin D1's cytoplasmic partner, CDK4, is also accumulated in the nucleus in response to $\mathrm{E}_{2}$ and this complex results in the first $\mathrm{pRb}$ phosphorylation at Thr 807/811 specifically in these epithelial cells 
(Tong \& Pollard 1999, Chen \& Pollard 2003). This appears to be a central node in the regulation of uterine epithelial cell proliferation by sex steroid hormones because progesterone, a hormone that completely inhibits the $\mathrm{E}_{2}$-induced uterine epithelial cell proliferation, blocks entry of cyclin D1 into the nucleus and completely inhibits $\mathrm{pRb}$ phosphorylation (Tong \& Pollard 1999). The importance of the mobilization of cyclin $\mathrm{D}$ in the $\mathrm{E}_{2}$ induced proliferative response is further emphasized by studies of cyclin D1 null mutant mice that undergo $\mathrm{E}_{2}$-induced proliferation through compensation by cyclin D2 that completely replaces cyclin D1 in its nuclear accumulation, CDK4 activation and phosphorylation of pRb (Chen \& Pollard 2003).

In both mice and humans, tamoxifen is an agonist in the uterus and an antagonist in the breast despite binding to the ER in both these tissues (Jordan \& Morrow 1999). The ER has two transcriptional activation domains, AF-1 and AF-2. AF-1 activity is stimulated by tamoxifen binding but AF-2 is inhibited (Smith et al. 1997, McDonnell 1999) while $\mathrm{E}_{2}$ activates both AF-1 and AF-2 (Webb et al. 1995, Smith et al. 1997, Jordan \& Morrow 1999). This results in the differential recruitment of receptor co-factors that could result in interpretation of estrogen signals as either inhibitory or stimulatory (Smith et al. 1997, Jordan \& Morrow 1999, Dutertre \& Smith 2000, Pearce et al. 2003). Tamoxifen has also been reported to have some non-receptor-mediated effects (Altan et al. 1999). Thus, it is an important question whether its proliferative effects in the uterus use the same mechanism as $\mathrm{E}_{2}$ or whether there is activation of alternative pathways. For example, there are reports that tamoxifen can activate cyclin E/CDK2 and thereby activate cell proliferation independently of cyclinD1/CDK4 (Dhillon \& Mudryj 2002).

In this report we show that tamoxifen induces luminal and glandular epithelial cell proliferation with a time course similar to $\mathrm{E}_{2}$. In these responses it acts as a classical impeded estrogen with about 200000 -fold lower potency than $E_{2}$ and never achieves a full estrogenic response. However, unlike other impeded estrogens such as estriol (Martin et al. 1976), its effects persist particularly upon the glandular epithelium and edema, suggesting longterm low level receptor occupancy. This results in cystic hyperplasia upon continuous administration (Martin \& Middleton 1978). The different estrogenic effects are also obviously differentially regulated by tamoxifen since a full response upon water imbibition is affected at doses that do not induce DNA synthesis, and these responses are greater and more persistent than observed with $\mathrm{E}_{2}$. This may suggest that as well as the proliferation regulation through the ER, there is some non-genomic action perhaps through the activation of VEGF (Hyder et al. 1996), known to be at least partially responsible for the edema in the uterus. It can also be concluded, as it has been by other workers (Carthew et al. 1999), that the uterotropic effects of an estrogen as measured by increased wet weight is not a reliable marker for the proliferative activity of these compounds. Interestingly, nuclear staining for PCNA, the $\delta$ sub-unit of DNA polymerase- $\alpha$, is also increased significantly over control levels at tamoxifen doses that do not affect DNA synthesis. Furthermore, the expression of PCNA in response to maximal doses of tamoxifen continues beyond the time when the cells are actively synthesizing DNA. PCNA expression and nuclear localization is often used as a surrogate marker for cell proliferation (Hyde-Dunn \& Jones 1997) but at least in the uterus it appears to be an unreliable marker for such events. Indeed, in the uterus it has been detected in apoptotic cells in the uterine lumen (Lai et al. 2000).

Despite these discrepancies in dose-response for some uterotropic activities, the action of tamoxifen upon the cell cycle machinery in the uterine epithelium is similar to that observed upon $\mathrm{E}_{2}$ stimulation. This cell proliferation as found after $E_{2}$ treatment is restricted to the luminal and glandular epithelium over the first $48 \mathrm{~h}$ of treatment, with no involvement of stromal cells. Tamoxifen causes the mobilization of cyclin D1 into the nucleus from the cytoplasm of these epithelial cells. This results in phosphorylation of the nuclear substrate, $\mathrm{pRb}$ and $\mathrm{p} 107$. Thereafter, cyclin E/CDK2 is activated, followed by a dramatic induction of cyclin $\mathrm{A}$, and a further elevation of CDK2 activity. This results in cells entering into S-phase co-incident with the nuclear localization of PCNA. The kinetics of these effects are similar to those seen in mice treated with $\mathrm{E}_{2}$ although the percentage of cells entering $\mathrm{S}$-phase is lower. Thus tamoxifen appears to regulate the uterine epithelial cell cycle through the same mechanism as $E_{2}$ and does not do so by triggering a down-stream event such as cyclin $\mathrm{E}$ expression independent of the canonical activation of cyclin D1/CDK4. Since the ER is essential for the $\mathrm{E}_{2}$-induced uterine proliferative responses (Korach 1994), these data suggest that activation of the AF-1 transcriptional regulatory sequences on the ER is sufficient to induce uterine epithelial cell proliferation. It will be interesting to study what aspect of ER activation is required for the $\mathrm{E}_{2}$-induced proliferation response in the mammary epithelium since tamoxifen inhibits this activity. Studies in cell culture have shown that this inhibitory effect is usually by suppression of cyclin D1 synthesis and induction of the CDIs, p18 ${ }^{\mathrm{INK} 4 \mathrm{C}}, \mathrm{p} 21^{\mathrm{WAF} 1}$ and p2 $7^{\mathrm{KIP} 1}$ (Planas-Silva \& Weinberg 1997, DoisneauSixou et al. 2003). In the uterus, these inhibitors do not appear to play essential roles in regulating cell proliferation since null mutations in them do not impair female fertility that is dependent upon this proliferation (Tong et al. 1998, Zindy et al. 2001). Thus the biological responses to tamoxifen in the uterus and mammary gland cells are opposite and therefore the definition of the molecular basis for them should help define the action of tamoxifen and $\mathrm{E}_{2}$ in different target tissues and provide a rationale for more selective therapies against estrogen-responsive breast cancers. 


\section{Acknowledgements}

The authors would like to thank Dr Liyin Zhu for advice on immunohistochemistry, Drs Yan Deng and A Niklaus for assistance with the figures and Dr A Niklaus for critical comments on the manuscript.

\section{Funding}

This work was supported by a grant from the NIH, R01 CA 89617 and the Albert Einstein College of Medicine Cancer Center, P30 CA 13330. J W P is the Sheldon and Betty E Feinberg Senior Faculty Scholar in Cancer Research. There is no conflict of interest that would prejudice the impartiality of this work.

\section{References}

Altan N, Chen Y, Schindler M \& Simon S 1999 Tamoxifen inhibits acidification in cells independent of the estrogen receptor. PNAS $964432-4437$.

Baum M 1997 Tamoxifen. Endocrine-Related Cancer 4 237-243.

Bergman L, Beelen ML, Gallee MP, Hollema H, Benraadt J \& van Leeuwen FE 2000 Risk and prognosis of endometrial cancer after tamoxifen for breast cancer. Comprehensive Cancer Centres' ALERT Group. Assessment of Liver and Endometrial Cancer Risk following Tamoxifen. Lancet 356 881-887.

Bocchinfuso WP \& Korach KS 1977 Mammary gland development and tumorigenesis in estrogen receptor knockout mice. Journal of Mammary Gland Biology and Neoplasia 2 323-334.

Carthew P, Edwards RE \& Nolan BM 1999 Uterotrophic effects of tamoxifen, toremifene, and raloxifene do not predict endometrial cell proliferation in the ovariectomized CD1 mouse. Toxicology and Applied Pharmacology 158 24-32.

Chen B \& Pollard JW 2003 Cyclin D2 compensates for the loss of cyclin D1 in estrogen-induced mouse uterine epithelial cell proliferation. Molecular Endocrinology 17 1368-1381.

Clarke CL \& Sutherland RL 1990 Progestin regulation of cellular proliferation. Endocrine Reviews 11 266-301.

Daniel CW, Silberstein GB \& Strickland P 1987 Direct action of 17 beta-estradiol on mouse mammary ducts analyzed by sustained release implants and steroid autoradiography. Cancer Research $\mathbf{4 7}$ 6052-6057.

Dhillon NK \& Mudryj M 2002 Ectopic expression of cyclin E in estrogen responsive cells abrogates antiestrogen mediated growth arrest. Oncogene 21 4626-4634.

Doisneau-Sixou SF, Sergio CM, Carroll JS, Hui R, Musgrove EA \& Sutherland RL 2003 Estrogen and antiestrogen regulation of cell cycle progression in breast cancer cells. Endocrine-Related Cancer 10 179-186.

Dutertre M \& Smith CL 2000 Molecular mechanisms of selective estrogen receptor modulator (SERM) action. Journal of Pharmacology and Experimental Therapeutics 295 431-437.

Ewen ME, Sluss HK, Sherr CJ, Matsushime K, Kato H \& Livingston DM 1993 Functional interactions of the retinoblastoma protein with mammalian D-type cyclins. Cell 73 487-497.

Fagg B, Martin L, Rogers LA, Clark BF \& Quarmby VE 1979 A simple method for preparing pure samples of uterine epithelial cells. Journal of Reproduction and Fertility 57 335-345.

Finn CA \& Martin L 1970 The role of the oestrogen secreted before oestrus in the preparation of the uterus for implantation in the mouse. Journal of Endocrinology 47 431-438.
Geng Y, Whoriskey W, Park MY, Bronson RT, Medema RH, Li T, Weinberg RA \& Sicinski P 1999 Rescue of cyclin D1 deficiency by knockin cyclin E. Cell 97 767-777.

Geum D, Sun W, Paik SK, Lee CC \& Kim K 1997 Estrogen-induced cyclin D1 and D3 gene expressions during mouse uterine cell proliferation in vivo: differential induction mechanism of cyclin D1 and D3. Molecular Reproduction and Development 46 450-458.

Haslam SZ 1988 Local versus systemically mediated effects of estrogen on normal mammary epithelial cell deoxyribonucleic acid synthesis. Endocrinology 122 860-867.

Hung H \& Pollak M 1995 Regulation of IGFBP-3 expression in breast cancer cells and uterus by estradiol and antiestrogens: correlations with effects on proliferation: a review. Progress in Growth Factor Research 6 495-501.

Hyde-Dunn J \& Jones GE 1997 Visualization of cell replication using antibody to proliferating cell nuclear antigen. In Basic Cell Culture Protocols, pp 341-349, edn 2. Eds JW Pollard \& JM Walker. Totowa, NJ: Humana Press.

Hyder SM, Stancel GM, Chiappetta C, Murthy L, Boettger-Tong HL \& Makela S 1996 Uterine expression of vascular endothelial growth factor is increased by estradiol and tamoxifen. Cancer Research $\mathbf{5 6}$ 3954-3960.

Ismail SM 1996 The effects of tamoxifen on the uterus. Current Opinions in Obstetrics and Gynecology 8 27-31.

Jordan VC \& Morrow M 1999 Tamoxifen, raloxifene, and the prevention of breast cancer. Endocrine Reviews 20 253-278.

Kaye AM, Sheratzky D \& Lindner HR 1972 Kinetics of DNA synthesis in immature rat uterus: age dependence and estradiol stimulation. Biochimica et Biophysica Acta 261 475-486.

Klotz DM, Hewitt SC, Korach KS \& Diaugustine RP 2000 Activation of a uterine insulin-like growth factor I signaling pathway by clinical and environmental estrogens: requirement of estrogen receptor-alpha. Endocrinology 141 3430-3439.

Korach KS 1994 Insights from the study of animals lacking functional estrogen receptor. Science 266 1524-1527.

Lai MD, Lee LR, Cheng KS \& Wing LY 2000 Expression of proliferating cell nuclear antigen in luminal epithelium during the growth and regression of rat uterus. Journal of Endocrinology 166 87-93.

Lee TH, Chuang LY \& Hung WC 1999 Tamoxifen induces p21 WAF1 and p27 KIP1 expression in estrogen receptor-negative lung cancer cells. Oncogene 18 4269-4274.

Lee TH, Chuang LY \& Hung WC 2000 Induction of p21 WAF1 expression via Sp1-binding sites by tamoxifen in estrogen receptor-negative lung cancer cells. Oncogene 19 3766-3773.

Lukas J, Herzinger T, Hansen K, Moroni MC, Resnitzky D, Helin K, Reed SI \& Bartek J 1997 Cyclin E-induced S phase without activation of the pRb/E2F pathway. Genes and Development $\mathbf{1 1}$ 1479-1492.

McDonnell D 1999 The molecular pharmacology of SERMs. Trends in Endocrinology and Metabolism 10 301-311.

Martin L \& Middleton E 1978 Prolonged oestrogenic and mitogenic activity of tamoxifen in the ovariectomized mouse. Journal of Endocrinology 78 125-129.

Martin L, Finn CA \& Trinder G 1973 Hypertrophy and hyperplasia in the mouse uterus after oestrogen treatment: an autoradiographic study. Journal of Endocrinology 56 133-144.

Martin L, Pollard JW \& Fagg B 1976 Oestriol, oestradiol-17ß and the proliferation and death of uterine cells. Journal of Endocrinology 69 $103-115$.

Matsushime H, Roussel MF, Ashmun RA \& Sherr CJ 1991 Colony-stimulating factor 1 regulates novel cyclins during the G1 phase of the cell cycle. Cell 65 701-713.

Matsushime H, Quelle DE, Shurtleff SA, Shibuya M, Sherr CJ \& Kato JY 1994 D-type cyclin-dependent kinase activity in mammalian cells. Molecular and Cellular Biology 14 2066-2076. 
Mueller MD, Pritts EA, Zaloudek CJ, Dreher E \& Taylor RN 2003 Regulation of vascular endothelial growth factor by tamoxifen in vitro and in vivo. Gynecologic and Obstetric Investigation 55 119-124.

Musgrove EA, Hamilton JA, Lee CSL, Sweeney KJE, Watts CKW \& Sutherland RL 1993 Growth factor, steroid, and steroid antagonist regulation of cyclin gene expression associated with changes in T-47D human breast cancer cell cycle progression. Molecular and Cellular Biology 13 3577-3587.

Musgrove EA, Lee CSL, Buckley MF \& Sutherland RL 1994 Cyclin D1 induction in breast cancer cells shortens G1 and is sufficient for cells arrested in G1 to complete the cell cycle. PNAS 91 8022-8026.

Ohtsubo M \& Roberts JM 1993 Cyclin-dependent regulation of G1 in mammalian fibroblasts. Science 259 1908-1912.

Pearce ST, Liu H \& Jordan VC 2003 Modulation of estrogen receptor alpha function and stability by tamoxifen and a critical amino acid (Asp-538) in helix 12. Journal of Biological Chemistry 278 7630-7638.

Planas-Silva MD \& Weinberg RA 1997 Estrogen-dependent cyclin E-cdk2 activation through p21 redistribution. Molecular and Cellular Biology 17 4059-4069.

Prall OWJ, Sarcevic B, Musgrove EA, Watts CKW \& Sutherland RL 1997 Estrogen-induced activation of cdk4 and cdk2 during G1-S phase progression is accompanied by increased cyclin D1 expression and decreased cyclin-dependent kinase inhibition association. Journal of Biological Chemistry 272 10882-10894.

Roberts JM 1999 Evolving ideas about cyclins. Cell 98 129-132.

Rumpel E, Michna H \& Kuhnel W 1995 PCNA immunoreactivity in the uterus of rats after treatment with the antiestrogen tamoxifen. Anatomischer Anzeiger 177 133-138.

Sartor BM, Sartor O \& Flanders KC 1995 Analogous tamoxifen and estrogen effects on transforming growth factor-betas 1 and 2 in the rat uterus. Reproductive Toxicology 9 225-231.

Sherr CJ 1994 G1 phase progression: cycling on cue. Cell 79 551-555.

Sherr CJ 1996 Cancer cell cycles. Science 274 1672-1677.

Sherr CJ \& Roberts JM 1999 CDK inhibitors: positive and negative regulators of G1-phase progression. Genes and Development $\mathbf{1 3}$ $1501-1512$.

Smith CL, Nawaz Z \& O’Malley BW 1997 Coactivator and corepressor regulation of the agonist/antagonist activity of the mixed antiestrogen, 4-hydroxytamoxifen. Molecular Endocrinology 11 $657-666$.
Sutherland R, Mester J \& Baulieu EE 1977 Tamoxifen is a potent 'pure' anti-oestrogen in chick oviduct. Nature 267 434-435.

Tong W \& Pollard JW 1999 Progesterone inhibits estrogen-induced cyclin D1 and cdk4 nuclear translocation, cyclin E, A-cdk2 kinase activation and cell proliferation in uterine epithelial cells in mice. Molecular and Cellular Biology 19 2252-2264.

Tong W \& Pollard JW 2002 Female Sex Steroid Hormone Regulation of Cell Proliferation in the Endometrium, pp 94-109. Eds SR Glasser, JD Aplin, LC Giudice \& S Tabibzadeh. London: Taylor \& Francis.

Tong W, Kiyokawa H, Soos TJ, Park M, Soares VC, Manova K, Pollard JW \& Koff A 1998 The absence of p27 $7^{\text {Kip } 1}$, an inhibitor of G1 cyclin-dependent kinases, uncouples differentiation and growth arrest during the granulosa $\rightarrow$ luteal transition. Cell Growth and Differentiation 9 787-794.

Travis RC \& Key TJ 2003 Oestrogen exposure and breast cancer risk. Breast Cancer Research 5 239-247.

Watts CK, Sweeney KJ, Warlters A, Musgrove EA \& Sutherland RL 1994 Antiestrogen regulation of cell cycle progression and cyclin D1 gene expression in MCF-7 human breast cancer cells. Breast Cancer Research and Treatment 31 95-105.

Webb P, Lopez GN, Ugt RM \& Kushner P 1995 Tamoxifen activation of the estrogen receptor/AP-1 pathway: potential origin for the cell-specific estrogen-like effects of antiestrogens. Molecular Endocrinology 9 443-456.

Wilcken NR, Prall OW, Musgrove EA \& Sutherland RL 1997 Inducible overexpression of cyclin D1 in breast cancer cells reverses the growth-inhibitory effects of antiestrogens. Clinical Cancer Research 3 849-854.

Willen R, Willen H \& Lindahl B 2002 Similarity of uterine mucosa changes in patients treated by raloxifen and tamoxifen. Anticancer Research 22 1121-1125.

Zindy F, den Besten W, Chen B, Rehg JE, Latres E, Barbacid M, Pollard JW, Sherr CJ, Cohen PE \& Roussel MF 2001 Control of spermatogenesis in mice by the cyclin D-dependent kinase inhibitors p18(Ink4c) and p19(Ink4d). Molecular and Cellular Biology 21 3244-3255.

Received 10 October 2004

Accepted 14 October 2004 